\title{
Ophthalmology and Clinical Research
}

ORIGINAL RESEARCH

\section{Refraction Data Survey, Ensemble \& Time Series Statistics during Adolescence}

\author{
Peter $R$ Greene, $P h D^{1^{*}}$, Otis S Brown, $E E^{2}$ and Ronald $M$ Berger, $O D^{3}$ \\ ${ }^{1} B G K T$ Consulting Ltd., Bioengineering, Huntington, New York, 11743, USA \\ ${ }^{2} \mathrm{C} \&$ O Research, Optics, Waynesboro, Pennsylvania, 17268, USA \\ ${ }^{3}$ O.D., Ellicott City, Maryland, 21042, USA

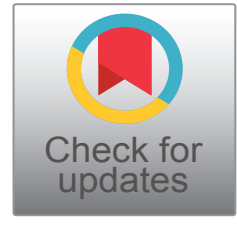

*Corresponding author: Peter R Greene, PhD., BGKT Consulting Ltd., Bioengineering, Huntington, New York, 11743, USA

\begin{abstract}
Purpose: The objective of this report is to quantify left eye to right eye refractive state differentials resulting from the accumulation of naturally occurring random fluctuations.

Methods: Clinical SER data from adolescent emmetropic human subjects are measured and analyzed in terms of ensemble and time-series <average value $>$ and $<$ RMS $>$ fluctuations of the left eye $\langle L>$, right eye $<R>$, and left-right differential $<L-R>$ measurement, $N=20$ subj.

Results: Results include random fluctuations for left and right eyes of human subjects age 11 to 23 years. Ensemble $R$ - $L$ differential measurement for this group is +/- 0.21 diopters RMS. Left-Right coupling ratio is $C R=0.88$ for both the differential $<L-R>$ and average $<L+R>/ 2$ control system input signals. Data from human subjects show individual fluctuations of +/- $0.15 \mathrm{D}$ to +/- $0.35 \mathrm{D}$ for the left and right eyes. Normal emmetropic eyes exhibit a slow and steady trend towards myopia, at the rate of -0.40 to -0.50 diopt./decade.

Conclusions: Ensemble and time-series results show that $15.9 \%$ of emmetropic adolescents are expected to progress into myopia during ages 12 to 22 years. Substantial shifts of greater than $+/-0.4$ diopters will produce a negative myopic exponential time constant response of the focal status of the eye. The aim of this study is to analyze cross-sectional (ensemble) and longitudinal (time series) results, both in terms of the <average $>$ trend line and <r.m.s. $>$ fluctuations about said line.
\end{abstract}

\section{Keywords}

Cross-sectional ensemble data, Longitudinal time-series data, Emmetropization, Progressive myopia, Feedback control systems, Left-right correlation, Refractive state data

\section{Introduction}

The equivalency of cross-sectional data (ensemble) and longitudinal data (time series) is a useful simplification, finding application in the study of emmtropization and myopia progression. In this report, RMS refractive state fluctuations, including $\left\langle L^{\wedge} 2\right\rangle$, $\left\langle R^{\wedge} 2\right\rangle,\left\langle(L+R)^{\wedge} 2>\right.$ and $\left\langle(L-R)^{\wedge} 2>\right.$ are reported for human and laboratory subjects. The differential RMS left-right disparity $\left.\operatorname{sqr}\left[<(L-R)^{\wedge} 2\right)>\right]$ is of fundamental importance for laboratory and clinical experiments.

\section{Literature review}

Irving, et al. [1], Li, Zhu, et al. [2], Goss \& Cox [3], Medina [4], and Greene \& Medina [5] present refraction-time data, addressing the basic problems of cross-sectional and longitudinal data for emmetropes and myopes.

\section{Myopia progression rates}

Greene \& Medina [5] show that cross-sectional data indicates myopia progression at a yearly rate of -0.49 diopters/year, consistent with the longitudinal data of Goss \& Cox [3] showing - 0.40 diopters/year myopia progression rate. Zadnik, et al. [6] show that a single refraction data point $R(t=t o)$ can determine the future likelihood of myopia progression. One of the best reports is by Fledelius \& Christensen [7] ( $N$ $=126$ subj.) where longitudinal ocular growth rates are mathematically determined from cross-sectional data. Oakley \& Young [8] and Greene, Grill \& Medina

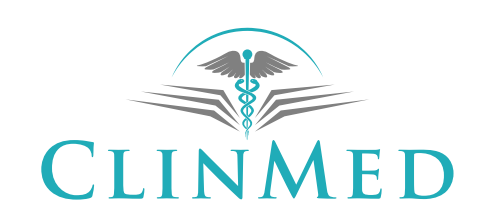

INTERNATIONAL LIBRARY
Citation: Greene PR, Brown OS, Berger RM (2019) Refraction Data Survey, Ensemble \& Time Series Statistics during Adolescence. Int J Ophthalmol Clin Res 6:107. doi.org/10.23937/2378-346X/1410107 Accepted: April 18, 2019: Published: April 20, 2019

Copyright: (C) 2019 Greene PR, et al. This is an open-access article distributed under the terms of the Creative Commons Attribution License, which permits unrestricted use, distribution, and reproduction in any medium, provided the original author and source are credited. 
[9] report myopia rates of -0.50 diopters/year, using both cross-sectional (ensemble) and longitudinal (time series) data techniques.

Ray \& O'Day [10] discuss the important problem of the statistical independence and correlation of left and right eye experimental data. Hung \& Ciuffreda [11] present a very detailed analysis and review of accommodation control systems and the stabilizing effects of plus lenses in the range +1.0 to +3.0 diopters. McBrien \& Adams [12] investigate cross-sectional and longitudinal techniques for determining myopia onset and progression in adults (ages $>21 \mathrm{yrs}$.), finding a refractive state change of -0.58 diopters of myopia over 2 years for $39 \%$ of the population sampled ( $N=37$ subjects).

Hooker, et al. [13] report refractive state fluctuations of $+/-0.30$ diopters RMS. Hung \& Smith [14] demonstrate that negative and positive lenses of strength -3.0 and +3.0 diopters can alter the refractive state of primates to the same amount as the strength of these applied lenses, on a time scale of 60 to 90 days.

\section{Myopia prevalence \& incidence}

In terms of myopia prevalence, Vitale, et al. [15] and Greene \& Medina [5] report that $38 \%$ to $42 \%$ of the U.S. population is myopic. Lin, et al. [16], Saxena, et al. [17], Pan, et al. [18], Saw, et al. [19] and Fan, et al. [20] present data from various demographics in Asia, indicating extreme myopia prevalence's of $40 \%$ to $95 \%$, according to the populations sampled. Interestingly, several studies report that myopia is correlated with I.Q. ${ }^{*}+$

\section{Terminology}

Medical problems similar to, but distinctly different from normal subject statistics presented here include amblyopia, anisometropia, and anisomyopia. It is emphasized that the data presented in Appendix Table 1 are from normal uncorrected emmetropic subjects. Sometimes after correction, these types of problems may result in a permanent $\mathrm{R}-\mathrm{L}$ differential.

The objective of this study is to analyze cross-sectional (ensemble) and longitudinal (time series) results, both in terms of the <average $>$ trend line and $<$ r.m.s. $>$ fluctuations about said line. The significance of this work is that the Ergodic Theorem from statistics allows us to equate cross-sectional data (ensemble average) with longitudinal data (time series) over reasonable time intervals, both in terms of the regression trend line (average data rate) and the +/- RMS scatter about said line. This is important in terms of studying progressive myopia development with an age-matched group (for instance, high school, college, or graduate students) typically showing -0.4 to -0.6 diopters of additional myopia per year.

\section{Materials and Methods}

\section{Numerical measurement of the eye's accuracy}

The normal human and primate eye maintains long-term focal accuracy in the presence of focal perturbations. Making reasonable assumptions based on a physiological model, produces an accurate value for the eye's focal accuracy.

\section{A focal control equation}

Laboratory experiments demonstrate that the normal eye adjusts its long-term focus by a dynamic process [21]. The exponential time-constant response of the eye to a focal perturbation in the eye's optical system is given by $[22,23]$

Eq. $(1) R(t)=$ Offset + Accom - Perturbation * EXP $(-t / \tau)$

While the equation can account for the eye's response, it cannot yield a direct measure of the eye's focal accuracy. The eye must overcome continuous micro-perturbations while growing to maintain accurate focus.

\section{Long-term dynamic system}

There is experimental evidence which suggests that each eye sets its long-term focus independently of the other eye [24]. In this study of myopia development, accommodation in one eye was prevented with atropine while the other was not. The results show the atropinized eye stabilized while the non-atropinized eye progressed into myopia. The model treats the left and right eye as two independently tracking mechanisms. Each eye uses its own accommodation signal to drive the long-term focal setting system [23]. Each eye has random noise in the actuator, i.e. perturbations in the focal status of the eye, Figure 1.

\section{Noise response of the eye's servo}

Sources of random noise in the optical system may include ordinary blinking, tear film variations, varying lighting conditions, contact lenses, so-called "spectacle blur" after removing contact lenses, variable intraocular pressure, seasonal variations, febrile disease, medical problems, the student's academic schedule, excessive use of alcohol, tobacco, marijuana, caffeine, drug sideeffects, excessive close work, etc.

The function $1 /(\tau s+1)$ for the eye's behavior has an exponential time-constant of $\sim 100$ days. The offset of the normal eye has a value of $\sim 1.5$ diopters. A Bode graph of this transfer function is shown, Figure 2 . The high frequency components of noise fluctuations are attenuated. The eye's focal status will change very slowly on a daily basis, -0.01 to -0.001 diopt/day.

\section{Frequency response plot}

The closed loop frequency response shows a break point at 100 days, and a frequency roll-off of $-6 \mathrm{DB} /$ 


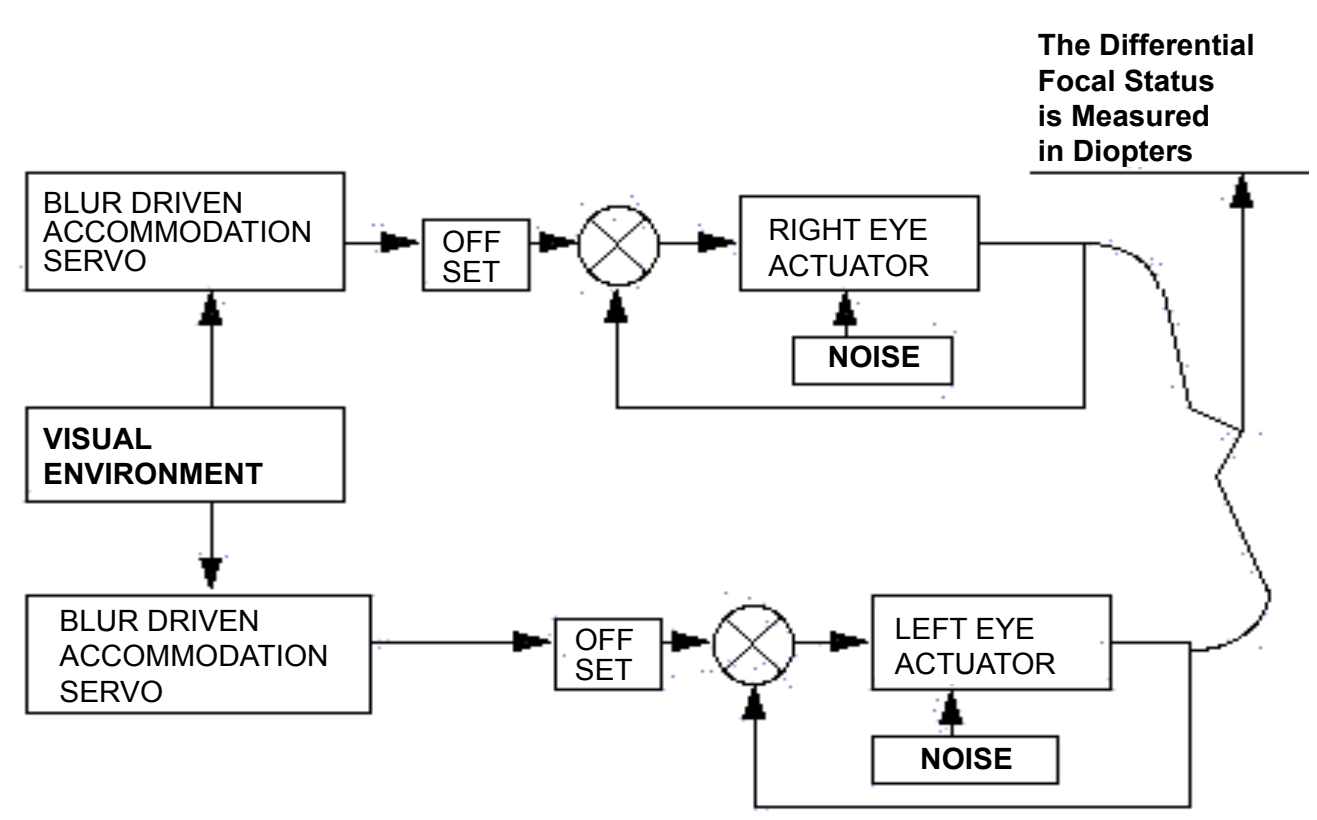

Figure 1: First-order closed-loop control systems are used to predict the behavior of the left and right eyes. Actuator noise perturbs the eye's focal state.

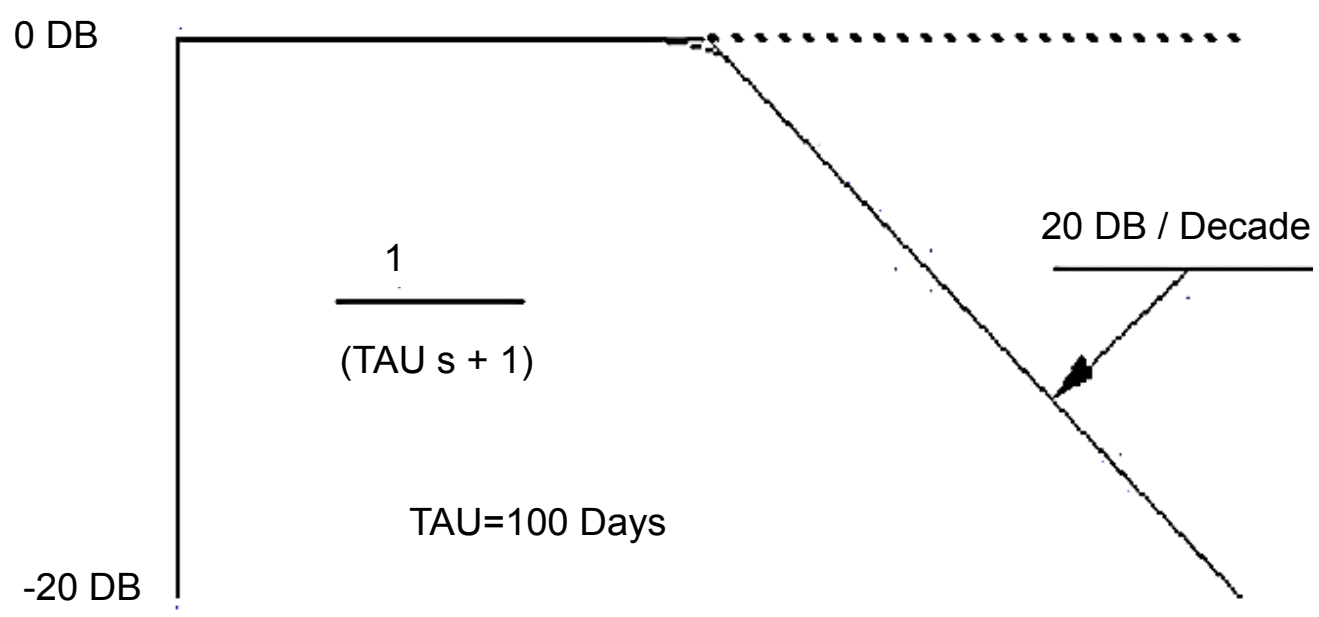

Figure 2: Bode plot showing the frequency response characteristics of a first-order control system with time constant $\tau=$ 100 days.

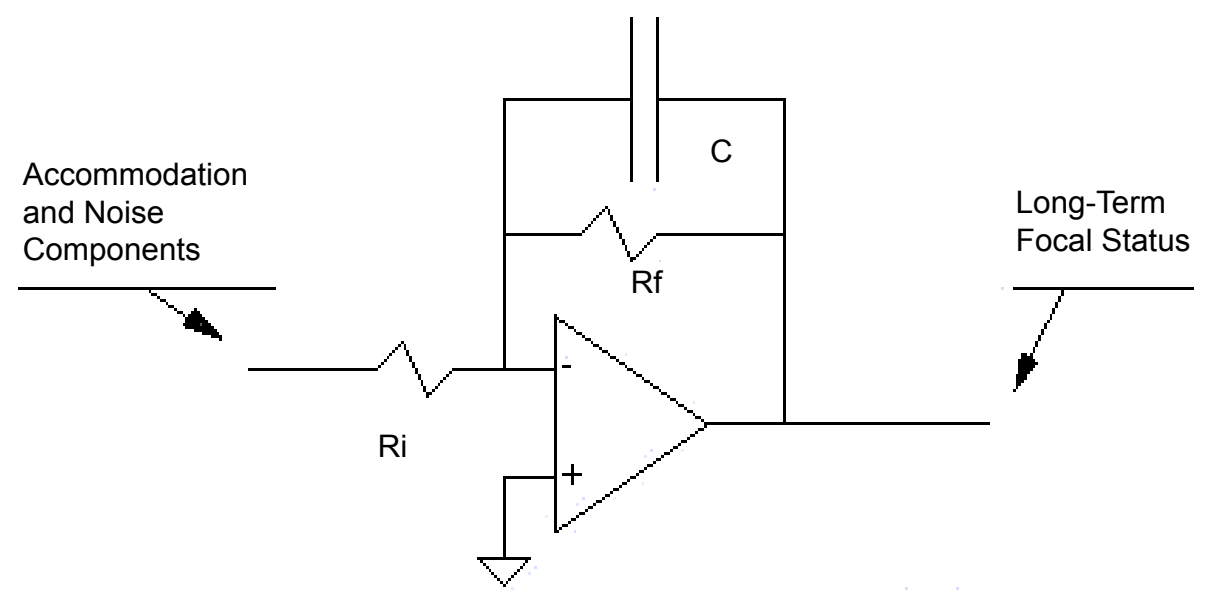

The dosed loop frequency response shows a break-point at 100 days and frequency roll-off of - 6 DB / Octave.

Figure 3: Analog computer representation of 1-st order control system with R-C feedback network. 
Octave. This transfer function can be modeled by an analog computer, Figure 2 and Figure 3.

\section{Differential measurement}

The focal states in Appendix Table 1 show the focal status of 20 individuals selected at random from the age of 11 to 23 . The RMS value is calculated from the differential measurement. Refractive state data in Appendix Table 1 are provided by the Berger Clinic [23] randomly selected from patient files. SER (spherical equivalent) refractions were subjective, noncycloplegic, accurate within +/- 0.25 D. Patients with normal vision were chosen for the statistical sample. Subject I.D. is deleted from the data record to maintain patient confidentiality. I.R.B. approval was granted.

\section{Perfect tracking accuracy}

If the eye's control system were perfect, the focal setting of the left eye would be identical to the right. The extent to which this is not the case will give us a means to determine the eye's tracking accuracy.

\section{Differential focal status Eqs}

We can measure the differential focal status developed between the left and right eye. This technique is based on the statistical principle that the squares of noise sources may be added algebraically.

Eq. (2) Differential $\wedge 2=$ Left Eye ${ }^{\wedge} 2+$ Right Eye ${ }^{\wedge} 2$

The same factors that produce perturbations in the left and right eye are equivalent for both eyes, assuming the underlying noise process is ergodic, which is highly probable for all normal eyes. Therefore, combining the noise statistic of the left and the right eyes:

Eq. (3) Differential ${ }^{\wedge} 2=2 *$ Individual ${ }^{\wedge} 2$

Taking the square root of both sides:

Eq. (4) Differential * $0.707=$ RMS noise in each eye

Using the equation in this form allows measurement of the differential focal status of an individual over a period of months. This sequence of measurements produces a continuing account of the eye's tracking accuracy, even though the average visual environment is changing. Measurement of noise by this technique is called the longitudinal or time-series of a stationary random process.

\section{Results}

\section{Electronics experiments}

To simulate time-series random fluctuations in refractive state of the left and right eyes, randomly oscillating voltage signals are created using standard chipsets and operational amplifiers available from Radio Shack (Archer Electonic Components). A 2-MHz digital storage oscilloscope was used, model DSO 112, manufactured in China. The quad op amps were \#324, with a band width of $10 \mathrm{kHz}$. Initial voltages supplied to the chips are +10 - and -10 -volts DC, yielding randomly fluctuating signals in the range $\mathrm{Vpp}=150$ millivolts. Simulated signals are shown in Figure 4 . AC voltage measurements of RMS confirm the basic equation for sums and differences $\operatorname{sqr}\left[<(R-L)^{\wedge} 2>\right]$ and $\operatorname{sqr}[<R$ $\left.+(>)^{\wedge} 2\right]$.

\section{A Representative noise programs}

In order to demonstrate how the changing focal status of the left and right eye generates a third differential noise statistic, a QBasic random number generator is programmed to simulate the noise in the left and right eyes, Figure 5 . $L(t)$ and $R(t)$ are assumed to fluctuate independently App. I. The program then calculates the differential measurement by subtracting the left eye's focal status from the right eye's focal status.

Eq. (5) Differential ${ }^{\wedge} 2=$ Left $^{\wedge} 2+$ Right $^{\wedge} 2$

$$
(.213)^{\wedge} 2=(.151)^{\wedge} 2+(.151)^{\wedge} 2
$$

The individual noise values in the program that produce the differential noise statistic are:

Eq. (6) Left $=+/-0.124$ diopt Right $=+/-0.174$ diopt
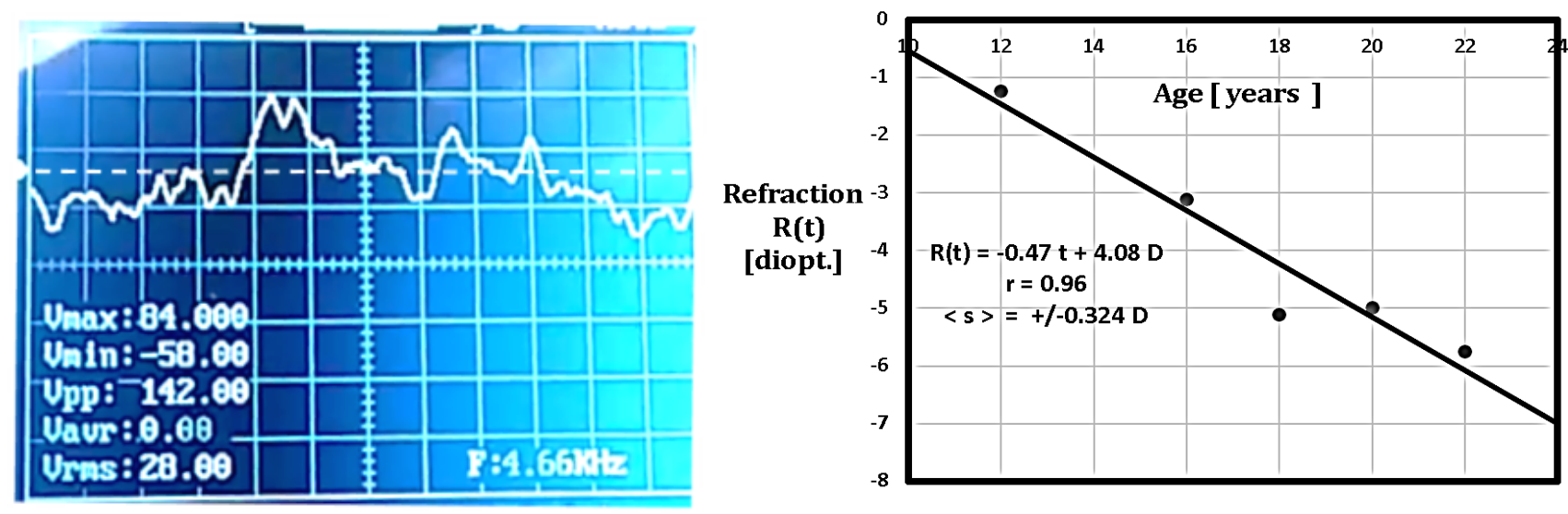

Figure 4: (a) Storage oscilloscope trace of stationary random time series, showing average $=\sim 0.0$ volts, RMS $=+/-27 \mathrm{mV}$;

(b) Longitudinal time-series refraction data from college student showing RMS = +/- $0.32 \mathrm{D}$ [Ref. 10]. 


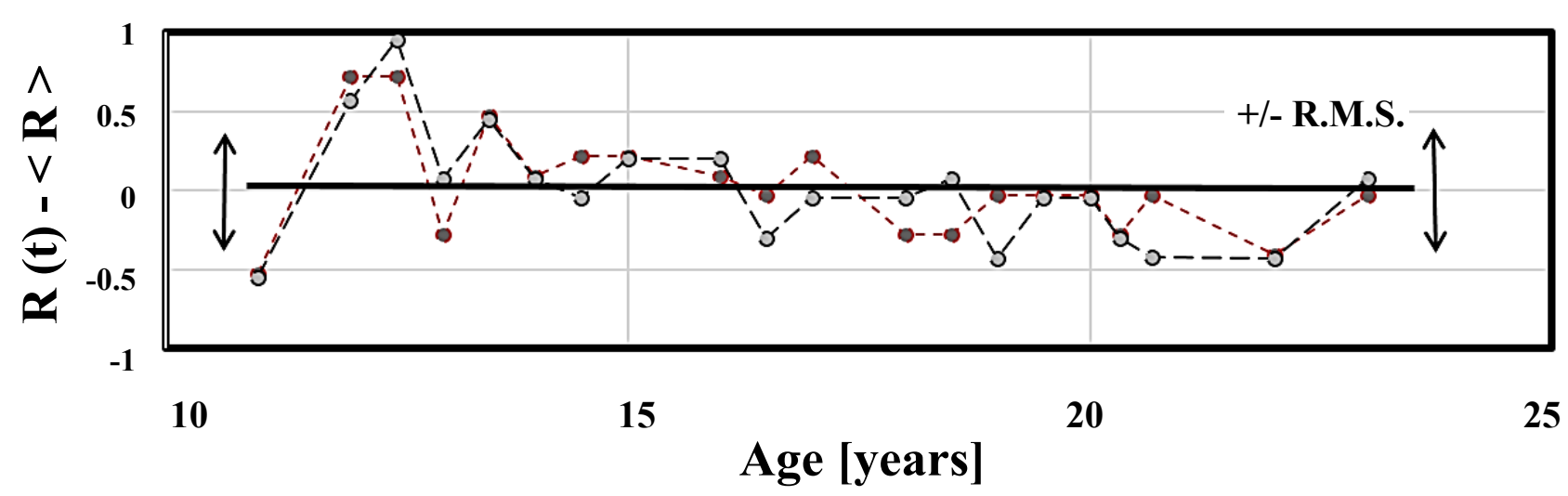

Figure 5a: Right $R(t)$ and Left $L(t)$ refractive states fluctuate about mean values $<R>$ and $<L>+/-0.34$ diopt. $R M S$.

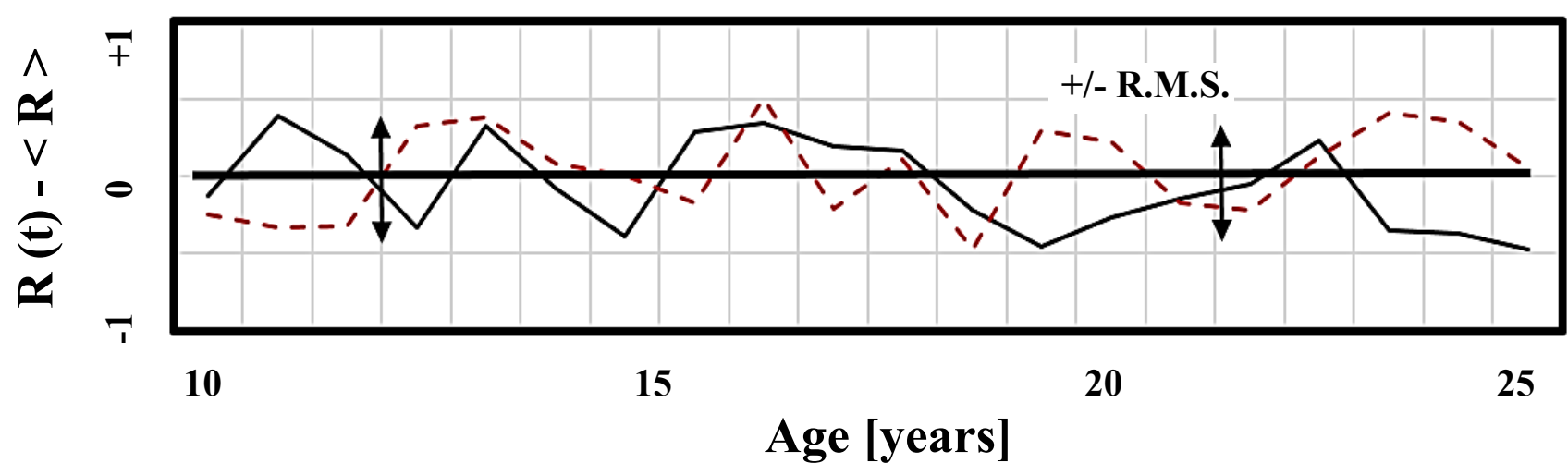

Figure 5b: Computer generated Right $R(t)$ and $L$ eft $L(t)$ refractive states fluctuate about mean values $<R>$ and $<L>+/-0.30$ diopt. RMS.

Table 1: Coupling Ratios, +/- RMS fluctuations.

\begin{tabular}{|l|l|l|l|l|}
\hline Subj & $\#$ & Coupling Ratio & RMS (L-R)^2 & Ref. \\
\hline RND(t) function & 1,000 & 0.0 & $+/-0.30 \mathrm{D}$ & Results, sect. \\
\hline Chicks & 8 & 0.50 & $+/-0.27 \mathrm{D}$ & Coletta, et al. [28] \\
\hline Marm-osets & 16 & n.a. & $+/-1.56 \mathrm{D}$ & Troilo, et al. [27] \\
\hline Rhesus & 9 & 0.97 & $+/-0.38 \mathrm{D}$ & Greene \& Guyton [10] \\
\hline Human & 20 & 0.88 & $+/-0.21 \mathrm{D}$ & Brown, et al. [23] \\
\hline
\end{tabular}

The average of these two numbers is 0.149 diopters RMS. Our estimate, calculated from the differential value, is +/- 0.15 to +/- 0.35 diopt. RMS.

\section{Ensemble differential measurement}

In dealing with stationary random processes, time averages are equivalent to ensemble averages. This is the classical Ergodic Theorem of statistics [25-30].

The ensemble differential measurement for this group of individuals is +/- 0.213 diopters RMS. The differential equation allows the calculation of the noise level in each individual eye:

Eq. (7) DIFFERENTIAL * .707 = INDIVIDUAL EYE NOISE

$$
(.213) * .707=+/-0.151 \text { Diopters RMS }
$$

Table 1 displays 4 comparable studies from the literature, showing that L-R fluctuations from $+/-0.2$ to
+/- 1.6 diopt. RMS are a normal part of the development process.

\section{Discussion}

Troilo, Totonelly and Harb [27] present data from marmosets showing left-right differentials of +/- 1.70 diopt. RMS during development, Table 1. Similarly, the random number function $\mathrm{RND}(\mathrm{t})$ is readily converted to a stationary random time-series $\mathrm{R}(\mathrm{t})=\mathrm{RND}(\mathrm{t})-$ 0.5 diopt. This produces totally independent $L$ and $R$ signals, with coupling ratio $C R=0.0$ and $\left\langle(L-R)^{\wedge} 2\right\rangle=+/-$ 0.3 diopt RMS, as shown in Table 1. Hooker, et al. [13] show random fluctuations in the range +/- 0.3 to +/- 0.6 diopters.

\section{Study limitations, future work}

One limitation of the Ergodic Theorem from statistics, as applied here to the time course fluctuations 
of human emmetropization data, is that while these statistical techniques accurately determine the average time series and RMS fluctuations about the trend line, they cannot predict the frequency or time-scale of these fluctuations (see Fig. 4). The reason for this is simple. With a single "snap-shot" of the cross-sectional data, the time scale is simply not available. However, our preliminary numerical work to date, using an FFT program, indicates that Fourier analysis of the crosssectional data does indeed reveal all the fundamental harmonic time components, for frequencies less rapid than the sampling frequency. In other words, in terms of retrieving maximum information from the data, the situation is better than expected, improving with large sample size, at smaller time intervals. Future work may try to address this challenging problem, in terms of extracting the Fourier component spectrum.

Figure 6, correlating left and right refractions, deserves some additional explanation. For this $\mathrm{N}=20$

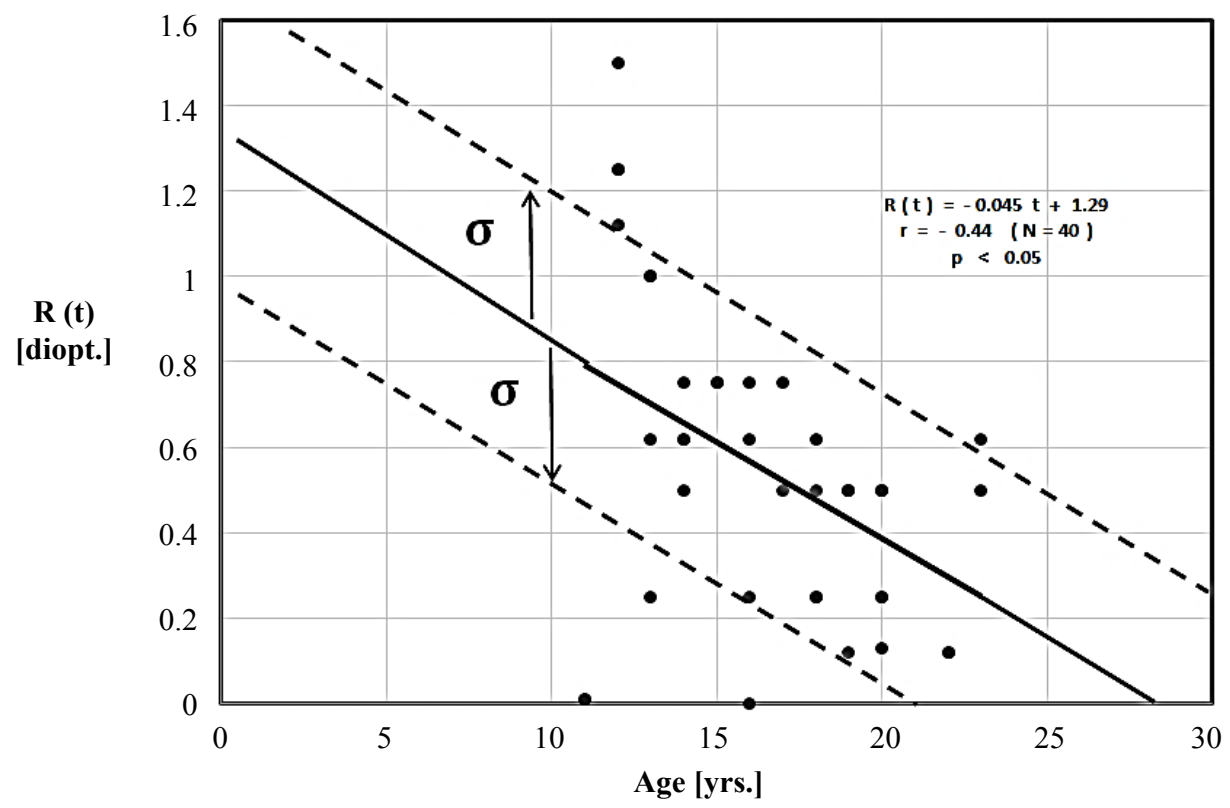

Figure 6a: Refractive status for $\mathrm{N}=40$ student eyes. Regression trend line indicates refractive state proceeds as $\mathrm{R}(\mathrm{t})=$ $-0.045 t+1.29$ diopters. Statistics $(+/-\sigma)$ indicate $15.9 \%$ are expected to progress into myopia during the period 12 to 22 years. An additional $34.1 \%$ will likely trend into myopia from 22 to 27 years.

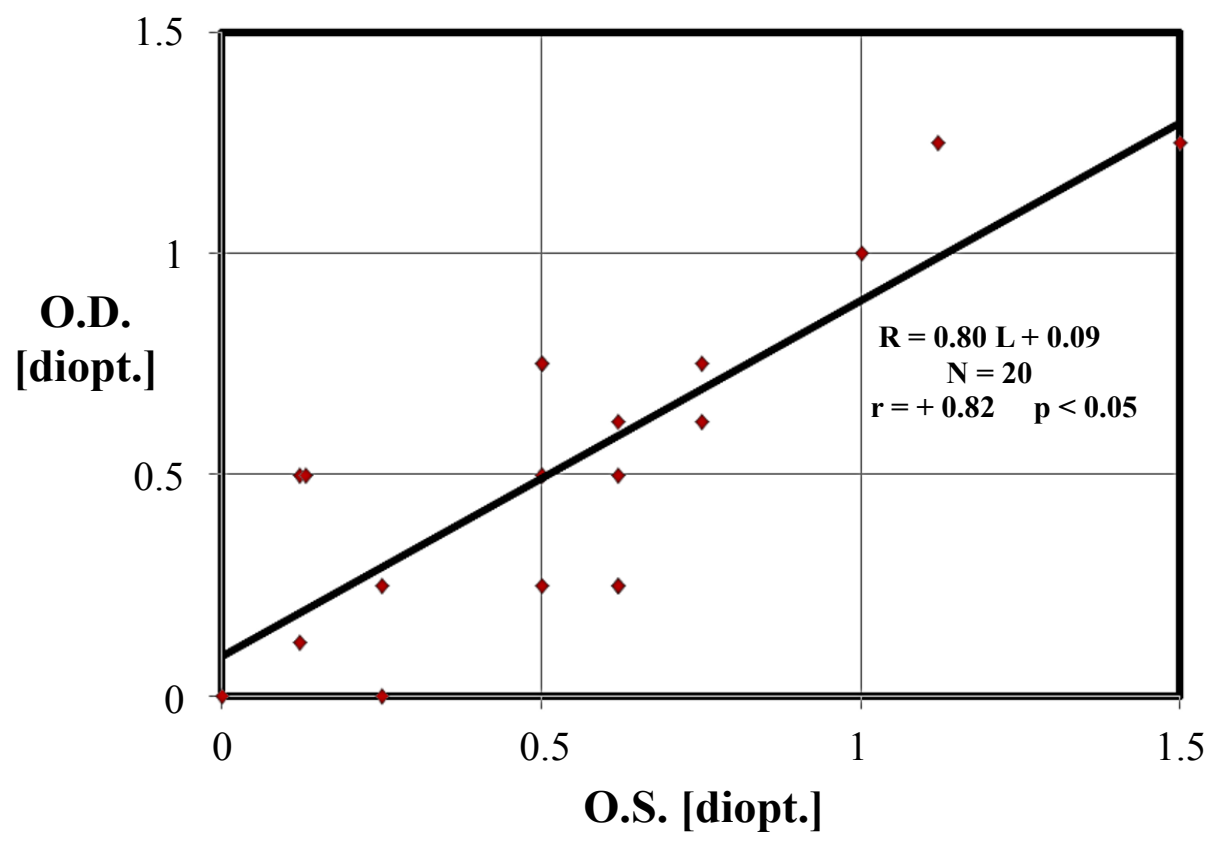

Figure 6b: Emmetropic human subjects have Left Eye (OS) refractive state L [ D.] partially correlated with the Right Eye (OD) $R$ [ D.], correlation coefficient $r=0.82, p<0.05$. The Left-Right disparity ratio is the regression slope 0.80 , indicating that the left and right refractions are approximately the same, within $\sim 20 \%$. Haegerstrom, et al. [25] present comparable results. 
subj. data set, it is only a co-incidence that both the line slope $b$ and regression $r$ have values about $\sim 0.8$. Strictly speaking, the regression line slope $(b=0.80$ for Figure 6$)$ is an indicator of the independence of the Left and Right refractions, whereas the correlation $(r=+0.82$ for Figure 6) coefficient is an indication of the quality, accuracy, or distribution of the data about said line. Note that for larger and larger data sets, the significance value $(p<$ $0.05)$ can improve to $p<0.0001$.

Previous experiments show the normal eye sets its long-term focus by a dynamic process. Physiological systems are complex and contain parameters which are not always clearly defined nor easily measured. Therefore, assumptions and simplifications are necessary in order to understand the long-term behavior of the normal eye. This requires insight into the fundamental behavior of optical systems in the presence of perturbations. Advanced statistical techniques establish the tracking accuracy of the normal eye Appendix 1.

\section{References}

1. Irving EL, Machan CM, Simpson T (2011) Longitudinal Changes in Human Refractive Error. Invest Ophthal \& Vis Sci 52: 2823.

2. Li Z, Zhu Z, Ding X, He M (2017) "Ten-year change of refractive error, anterior chamber depth and axial length in southern Chinese children". Invest Oph Vis Sci 58: 4425.

3. Goss DA, Cox VD (1985) Trends in the change of clinical refractive error in myopes. J Am Optometric Assoc 56: 608613.

4. Medina A (1980) El origen de las ametropías: ¿ qué es emetropía?" Archivos de la Sociedad Española de Oftalmología 40: 156-161.

5. Greene PR, Medina A (2016) Refraction data survey: 2nd generation correlation of myopia. Int'l ophthalmology 36 : 609-614.

6. Zadnik K, Sinnott LT, Cotter SA, Jones-Jordan LA, Kleinstein RN, et al. (2015) Prediction of Juvenile-Onset Myopia. JAMA Ophthalmol 133: 683-689.

7. Fledelius HC, Christensen AC (1996) Reappraisal of the human ocular growth curve in fetal life, infancy, and early childhood. Br J Ophthalmol 80: 918-921.

8. Oakley KH, Young FA (1975) Bifocal control of myopia. Am J Optom Physiol Opt 52: 758-764.

9. Young FA (1963) Reading, measures of intelligence and refractive errors. Optometry and Vision Science. 40: 257264.

10. Greene PR, Grill ZW, Medina A (2016) Mathematical Models of College Myopia. Optik (Stuttg) 127: 896-899.

11. Hung GK, Ciuffreda KJ (2000) Quantitative analysis of the effect of near lens addition on accommodation and myopigenesis. Curr Eye Res 20: 293-312.

12. McBrien NA, Adams DW (1997) A longitudinal investigation of adult-onset and adult-progression of myopia in an occupational group, Refractive and biometric findings. Invest Ophth \& Vis Sci 38: 321-333.

13. Hooker RJ, Brown OS, Greene PR, Moore JS, Colgate SA (1996) Analog computer simulation of accommodation. EMBS Engineering in Medicine and Biology Soc Proc 18th
Annual Int'I Conf IEEE 5: 1777-1779.

14. Hung LF, Crawford ML, Smith EL (1995) Spectacle lenses alter eye growth and the refractive status of young monkeys. Nat Med 1: 761-765.

15. Vitale S, Sperduto RD, Ferris FL (2009) Increased prevalence of myopia in the United States between 19711972 and 1999-2004. Arch Ophthalmol 127: 1632-1639.

16. Lin LL, Shih YF, Lee YC, Hung PT, Hou PK (1996) Changes in ocular refraction and its components among medical students--a 5-year longitudinal study. Opt Vis Sci 73: 495498.

17. Saxena R, Vashist $P$, Tandon R, Pandey RM, Bhardawaj $A$, et al. (2017) Incidence and progression of myopia and associated factors in urban school children in Delhi: The North India Myopia Study (NIM Study). PLoS One 12: e0189774.

18. Pan CW, Ramamurthy D, Saw SM (2012) Worldwide prevalence and risk factors for myopia. Ophthal Physiol Opt 32: 3-16.

19. Saw SM, Tong L, Chua WH, Chia KS, Koh D, et al. (2005) Incidence and progression of myopia in Singaporean school children. Invest Ophthalmol Vis Sci 46: 51-57.

20. Fan DS, Lam DS, Lam RF, Lau JT, Chong KS, et al. (2004) Prevalence, incidence, and progression of myopia of school children in Hong Kong. Invest Ophthalmol Vis Sci 45: 10711075.

21. Young FA (1961) The Effect of Restricted Visual Space on the Primate Eye. Am J Ophthal 52: 799-806.

22. Brown OS, Young FA (1981) The Response of a Servo Controlled Eye to a Confined Visual Environment. Biomed Sci Instrum 17: 41-44.

23. Brown OS, Young FA, Berger RM (1981) Measuring the Eye's Focal Accuracy: A Heuristic Approach," IEEE EMBS Conf 3:64-68, 1981. A predictive mathematical model for the eye's focal status.

24. Bedrossian RH (1971) The effect of atropine on myopia. Annals Ophthal 3: 891-897.

25. Haegerstrom PG, Schneck ME, Lott LA, Hewlett SE, Brabyn JA (2014) Longitudinal increase in anisometropia in older adults. Opt Vis Sci 91: 60-67.

26. Williams KM, Hysi PG, Yonova-Doing E, Mahroo OA, Snieder H, et al. (2017) Phenotypic and genotypic correlation between myopia and intelligence. Scientific reports 7: 45977.

27. Troilo D, Totonelly K, Harb E (2009) Imposed anisometropia, accommodation, and regulation of refractive state. Opt Vis Sci 86: 31-39.

28. Coletta NJ, Marcos S, Wildsoet C, Troilo D (2003) Doublepass measurement of retinal image quality in the chicken eye. Opt Vis Sci 80: 50-57.

29. James HM, Nichols NB, Phillips RS (1947) Theory of Servomechanisms. Mcgraw-Hill, NY, USA, 6: 271.

30. Schwartz M (1970) Information transmission, modulation and noise: a unified approach to communication systems. McGraw-Hill NY, USA.
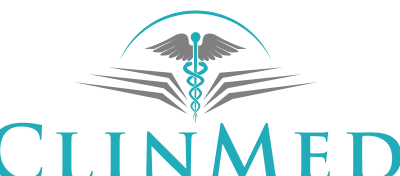

INTERNATIONAL LIBRARY 


\section{Appendix I}

\section{Human Emmetropia Data}

Different species have different degrees of overlap and coupling, i.e. linked focusing, between the visual fields of the left and right eyes. For instance, birds have more-or-less independent focusing of the left $L(t)$ and right $\mathrm{R}(\mathrm{t})$ eyes, so we expect the Coupling Ratio $\mathrm{CR}=$ 0.0 to 0.5 , whereas primates have considerable visual field overlap, so a $C R$ in the range $0.5<C R<1.0$ is expected, Figure 6 and Table 1.

The Coupling Ratio CR is directly related to the crossproduct term, when computing statistical averages of fluctuating sums and differences. For example, average sum $<R+L>$ and difference $<R-L>$ of the accommodation of the Left $L(t)$ and Right $R(t)$ eyes is:

$$
\begin{aligned}
& \text { Eq. A-1 RMS Difference }\langle\mathrm{R}-\mathrm{L}\rangle \\
& \left\langle(\mathrm{L}-\mathrm{R})^{\wedge} 2\right\rangle=\left\langle\mathrm{L}^{\wedge} 2\right\rangle-2 * \mathrm{CP} *\left\langle\mathrm{~L}^{*} \mathrm{R}\right\rangle+\left\langle\mathrm{R}^{\wedge} 2\right\rangle \\
& <0.0444>=<0.123>-2 * \text { CP }<0.219>+<0.129 \\
& \left.\mathrm{RMS}=\operatorname{sqr}\left(<(\mathrm{R}-\mathrm{L})^{\wedge} 2\right\rangle\right)=+/-0.213 \mathrm{D}, \mathrm{CP}=+\mathbf{0 . 8 8}
\end{aligned}
$$

Eq. A-2 RMS Summation $\langle\mathrm{R}+\mathrm{L}\rangle$

$$
\begin{aligned}
& <(L+R)^{\wedge} 2>=\left\langle L^{\wedge} 2>+2 * C P *<L^{*} R>+<R^{\wedge} 2\right\rangle \\
& <0.458>=<0.123>+2 * C P *<0.219>+<0.129> \\
& \text { RMS }=\operatorname{sqr}\left(<(R+L)^{\wedge} 2>\right)=+/-0.677 \mathrm{D}, C P=+0.88
\end{aligned}
$$

Note that for $\mathrm{CP}=0$, i.e. zero coupling between the left and right eyes, typical of birds, the SUM and DIFFERENCE Eqs. A-1 and A-2 produce the same result, because the cross-product term $-2^{*} C P^{*}<L^{*} R>$ disappears: RMS)

Eqs. $\left.A-3<(L-R)^{\wedge} 2\right\rangle=\left\langle L^{\wedge} 2\right\rangle+\left\langle R^{\wedge} 2\right\rangle$ (difference

$$
\left\langle(L+R)^{\wedge} \mathbf{2}\right\rangle=\left\langle L^{\wedge} 2\right\rangle+\left\langle R^{\wedge} \mathbf{2}\right\rangle \text { (summation RMS) }
$$

Computer results for developing chicks indicate $\mathrm{CP}$ $=0.5$ with the emmetropia data of Coletta, et al. [28]. Results shown in Figure 6 and Appendix Table 1 indicate +/- RMS fluctuations of +/- 0.351 D and +/- 0.359 D for Right and Left eyes.

\section{Acknowledgements}

This work was supported in part by C \& O Research, BGKT Engineering, and NIH-NEI Grant \# EY 05013. Special thanks to Frank Young, David Guyton, and Antonio Medina for many helpful discussions.

\section{Declaration of Interest}

The authors have no proprietary or financial conflicts of interest.

\section{Nomenclature}

$\mathrm{R}(\mathrm{t})=$ refractive state [diopters] at time $\mathrm{t}$ [yrs.]

\begin{tabular}{|c|c|c|c|c|c|c|c|c|c|c|}
\hline Age & $R(t)$ & $L(t)$ & (R -L) & $(\mathrm{L}-\mathrm{R})^{\wedge} \mathbf{2}$ & $\mathbf{R}-\langle\mathbf{R}\rangle$ & $L-<L>$ & $R^{\wedge} \mathbf{2}$ & L^2 & $(R+L)^{\wedge} 2$ & $L * R$ \\
\hline 14 & 0.75 & 0.50 & 0.25 & 0.063 & 0.22 & -00.05 & 0.0484 & 0.0025 & 0.0289 & -00.00012 \\
\hline 19 & 0.50 & 0.12 & 0.38 & 0.144 & -00.03 & -00.43 & 0.0009 & 0.185 & 0.217 & 0.00017 \\
\hline 20 & 0.50 & 0.50 & 0.00 & 0 & -00.03 & -00.05 & 0.0009 & 0.0025 & 0.0064 & 0.0015 \\
\hline 11 & 0.00 & 0.00 & 0.00 & 0 & -00.53 & -00.55 & 0.281 & 0.301 & 10.17 & 0.292 \\
\hline 16 & 0.62 & 0.75 & -0.13 & 017 & 0.09 & 0.20 & 0.0081 & 0.04 & 0.0841 & 0.018 \\
\hline 22 & 0.12 & 0.12 & 0.00 & 0 & -00.41 & -00.43 & 0.168 & 0.185 & 0.706 & 0.176 \\
\hline 12 & 10.25 & 10.12 & 0.13 & 0.017 & 0.72 & 0.57 & 0.518 & 0.325 & 10.66 & 0.410 \\
\hline 16 & 0.00 & 0.25 & -0.25 & 0.063 & -00.03 & -00.30 & 0.0009 & 0.09 & 0.109 & 0.009 \\
\hline 18 & 0.25 & 0.62 & -0.37 & 0.143 & -00.28 & 0.07 & 0.0784 & 0.0049 & 0.0441 & -00.0196 \\
\hline 13 & 10.00 & 10.00 & 0.00 & 0 & 0.47 & 0.45 & 0.221 & 0.203 & 0.846 & 0.216 \\
\hline 19 & 0.50 & 0.50 & 0.00 & 0 & -00.03 & -00.05 & 0.0009 & 0.0025 & 0.0064 & 0.0015 \\
\hline 17 & 0.75 & 0.50 & 0.25 & 0.063 & 0.22 & -00.05 & 0.0484 & 0.0025 & 0.0289 & -00.011 \\
\hline 20 & 0.25 & 0.25 & 0.00 & 0 & -00.28 & -00.30 & 0.0784 & 0.09 & 0.336 & 0.084 \\
\hline 12 & 10.25 & 10.50 & -0.25 & 0.063 & 0.72 & 0.95 & 0.518 & 0.903 & 20.79 & 0.684 \\
\hline 14 & 0.62 & 0.62 & 0.00 & 0 & 0.09 & 0.07 & 0.0081 & 0.0049 & 0.0256 & 00.0063 \\
\hline 13 & 0.25 & 0.62 & -0.37 & 0.143 & -00.28 & 0.07 & 0.0784 & 0.0049 & 0.0441 & -00.0198 \\
\hline 15 & 0.75 & 0.75 & 0.00 & 0 & 0.22 & 0.20 & 0484 & 0.04 & 0.176 & 0.044 \\
\hline 20 & 0.50 & 0.13 & 0.37 & 0.143 & -00.03 & -00.42 & 0.0009 & 176 & 0.203 & 0.013 \\
\hline 18 & 0.25 & 0.50 & -0.25 & 0.063 & -00.28 & -00.05 & 0.0784 & 0.0025 & 0.109 & 0.014 \\
\hline 23 & 0.50 & 0.62 & -0.12 & 0.016 & -00.03 & 0.07 & 0.0009 & 0.0049 & 0.0016 & -00.0021 \\
\hline
\end{tabular}

TAU $=\boldsymbol{\tau}=$ exponential time constant $\sim 100$ days

$\mathrm{CR}=$ left-right coupling ratio, $0.0<\mathrm{CR}<1.0$ (App. I)

$\left.\mathrm{RMS}=\operatorname{sqr}\left[<(\mathrm{L}-\mathrm{R})^{\wedge} 2\right\rangle\right]$

$\mathrm{dR}=$ refractive state fluctuations $\sim+/-0.1$ to $+/-0.3$ diopt.

$\langle f(t)\rangle=<$ average value $>$ over time $T=(1 / T) \int f(t) d t$

Appendix Table 1: Refractive State Data. ( $L=O S$ [ diopt.], $R=O D$ [ diopt.], $t=$ age [yrs.]).

Results:

< Aver0. > <+00.53> <+00.55> _... < <0.0455> 